\title{
Finite element method studies on the transmission of masticatory force to the bone substrate via titanium and zirconium implants
}

\author{
Studii prin metoda elementelor finite asupra transmiterii \\ forţelor masticatorii către substratul osos prin intermediul \\ implanturilor din titan şi zirconie
}

\author{
Sabina David ${ }^{1}$, Ioan Sârbu', Raluca Monica Comăneanu' ${ }^{2}$, Dan Nicolae Pătroi² \\ ${ }^{1}$ Facultatea de Medicină Dentară, Universitatea de Medicină şi Farmacie „Carol Davila“, Bucureşti, România \\ ${ }^{2}$ Facultatea de Medicină Dentară, Universitatea „Titu Maiorescu“, Bucureşti, România
}

\begin{abstract}
In this study we compared the modalities of transmitting experimental masticatory forces through titanium or zirconium dental implants to the bone substrate. According on the finite element analysis, the biomechanical behavior of the zirconium implant is better than the biomechanical behavior of the titanium implant, because the zirconium implant, by its features, attenuates the transfer of stresses between it and the bone, keeping osteointegration.
\end{abstract}

Keywords: dental implant, titanium, zirconium, finite element analysis

\section{REZUMAT}

În prezentul studiu, am analizat comparativ modalităţile de transmitere a forţelor masticatorii experimentale prin intermediul implanturilor dentare din titan sau zirconie (oxidul de zirconiu) asupra substratului osos. Pe baza analizei cu elemente finite efectuate, comportamentul biomecanic al implantului din zirconie este mai bun decât comportamentul biomecanic al implantului din titan, deoarece implantul din zirconie, prin caracteristicile sale, atenuează transferul tensiunilor dintre el şi os, menajând osteointegrarea.

Cuvinte cheie: implant dentar, titan, zirconie, analiză cu elemente finite

\section{INTRODUCERE}

Analiza cu elemente finite (FEA) se poate utiliza pentru a investiga designul implanturilor dentare, structura şi materialele din care sunt confecționate restaurările protetice şi stabilitatea osului înconjurător (1). În domeniul medical, comportamentul oricărei structuri sau țesut stimulat într-un anumit mod poate fi analizat cu FEA (2). În plus, FEA permite măsurarea distribuției tensiunilor în interiorul osului şi a diferitelor modele de implant dentar în timpul efectuării masticației, măsurători imposibil de realizat in vivo $(1,3)$.
Multe articole recente (4-23) au prezentat utilizarea FEA pentru a evalua distribuția tensiunilor de la nivelul implantului în osul înconjurător, concentrându-se pe diferite lungimi şi forme ale implanturilor, precum şi pe designul protezelor şi pe modul de conectare a acestora la implanturi.

Scopul prezentului studiu a fost acela de a analiza comparativ prin metoda elementelor finite modul de transmitere al forțelor masticatorii către substratul osos prin implanturi din titan şi zirconie, pentru a depista care dintre cele două implanturi prezintă un comportament biomecanic mai bun în regiunea laterală mandibulară. 


\section{MATERIAL ŞI METODĂ}

În studiu am luat două implanturi, din titan şi din zirconie, pe care le-am scanat 3D şi le-am inserat virtual în mandibula unui pacient $\mathrm{cu}$ edentaţie de 36 .

Modelul osului mandibular 1-am obținut din examenul CBCT efectuat de pacient, pe care 1-am importat şi prelucrat în softul Mimics ${ }^{\circledR}$. Ulterior, am inserat succesiv cele două tipuri de implanturi în zona edentată, simulând osteointegrarea acestora prin blocarea deplasărilor în ansamblul os-implant.

Cele două modele astfel pregătite au fost importate în $\mathrm{ANSYS}^{\circledR}$, program cu ajutorul căruia am efectuat analiza cu elemente finite. Am aplicat asupra celor două implanturi, la temperatura de $36^{\circ} \mathrm{C}$, o forță experimentală de $200 \mathrm{~N}$, care s-a descompus vectorial pe 3 direcții, rezultând în final:

- O forță de $34.76 \mathrm{~N}$ pe axa OX;

- O forță de $139.28 \mathrm{~N}$ pe axa OY;

- O forță de $-139.26 \mathrm{~N}$ pe axa OZ.

\section{REZULTATE OBTIINUTE}

Analiza cu elemente finite a fost efectuată într-o primă etapă asupra implantului dentar din aliaj de titan. Primul model experimental alcătuit din osul mandibular al pacientului şi implantul osteointegrat din aliaj de titan au cuprins după discretizare 98.568 elemente finite şi 166.405 noduri.

Caracteristicile materialelor ce compun modelul 1 , introduse în programul de analiză prin metoda elementelor finite, sunt prezentate în Tabelele 1-3.

TABELUL 1. Proprietăți izotrope de elasticitate ale aliajului din titan din care este confecționat implantul

\begin{tabular}{|c|c|c|c|}
\hline $\begin{array}{c}\text { Modul Young } \\
\text { (MPa) }\end{array}$ & $\begin{array}{c}\text { Coeficientul } \\
\text { Poisson }\end{array}$ & $\begin{array}{c}\text { Modul Bulk } \\
\text { (MPa) }\end{array}$ & $\begin{array}{c}\text { Modul de } \\
\text { forfecare (MPa) }\end{array}$ \\
\hline $1,138 \mathrm{e}+005$ & 0,342 & $1,2004 \mathrm{e}+005$ & 42399 \\
\hline
\end{tabular}

TABELUL 2. Proprietăți izotrope de elasticitate ale osului cortical

\begin{tabular}{|c|c|c|c|}
\hline $\begin{array}{c}\text { Modulul Young } \\
\text { (MPa) }\end{array}$ & $\begin{array}{c}\text { Coeficientul } \\
\text { Poisson }\end{array}$ & $\begin{array}{c}\text { Modulul Bulk } \\
\text { (MPa) }\end{array}$ & $\begin{array}{c}\text { Modul de } \\
\text { forfecare (MPa) }\end{array}$ \\
\hline 10000 & 0.3 & 8333.3 & 3846.2 \\
\hline
\end{tabular}

TABELUL 3. Rezistența la compresiune elastică a osului cortical

Rezistența la compresiune elastică (MPa) 975

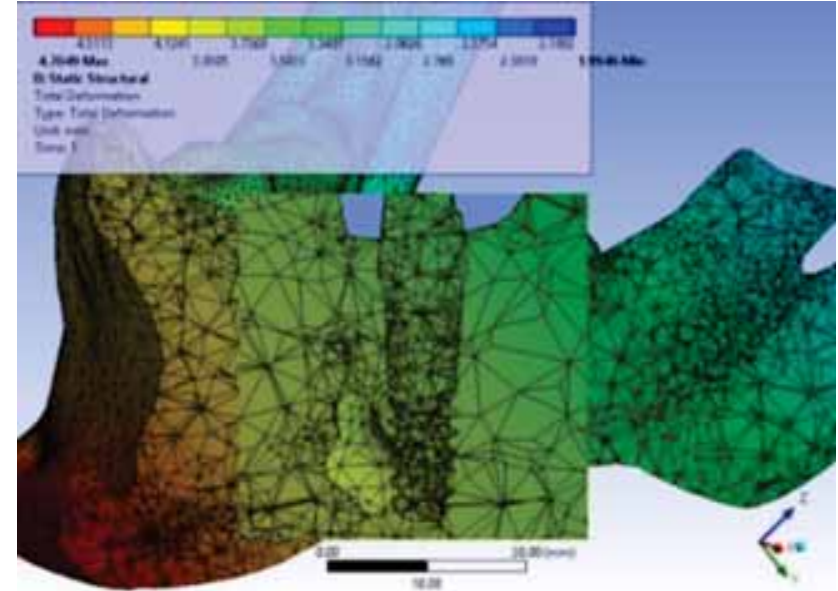

FIGURA 1. Deformația absolută totală a modelului 1

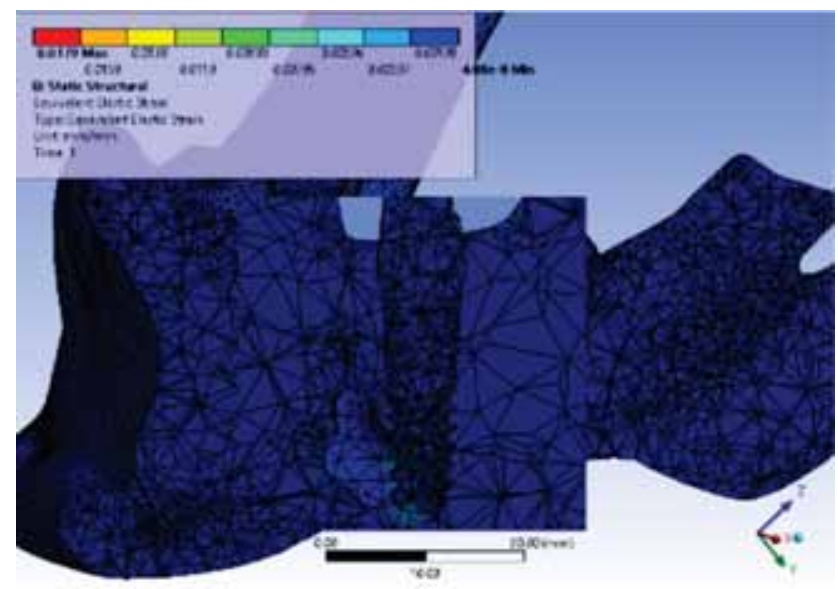

FIGURA 2. Deformația relativă elastică echivalentă a modelului 1

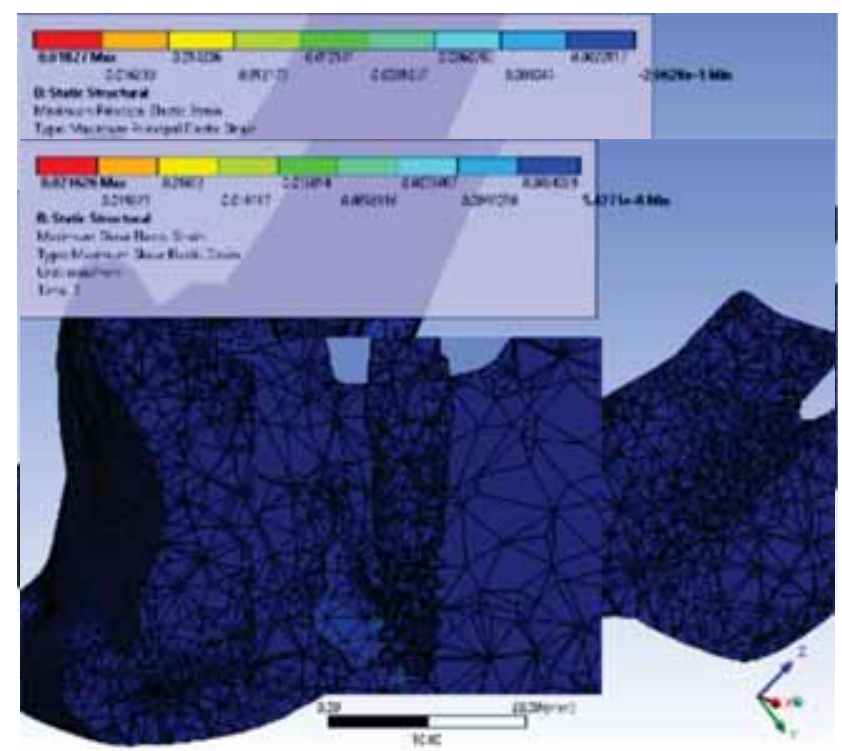

FIGURA 4. Deformația relativă elastică tangențială maximă a modelului 1

Deformația absolută totală a modelului 1 a variat între un minim de $1,9946 \mathrm{~mm}$ şi un maxim de $4,7049 \mathrm{~mm}$, iar valorile deformației totale la nive- 
lul elementelor implantului sunt medii spre mari comparativ cu cele de la nivelul mandibulei.

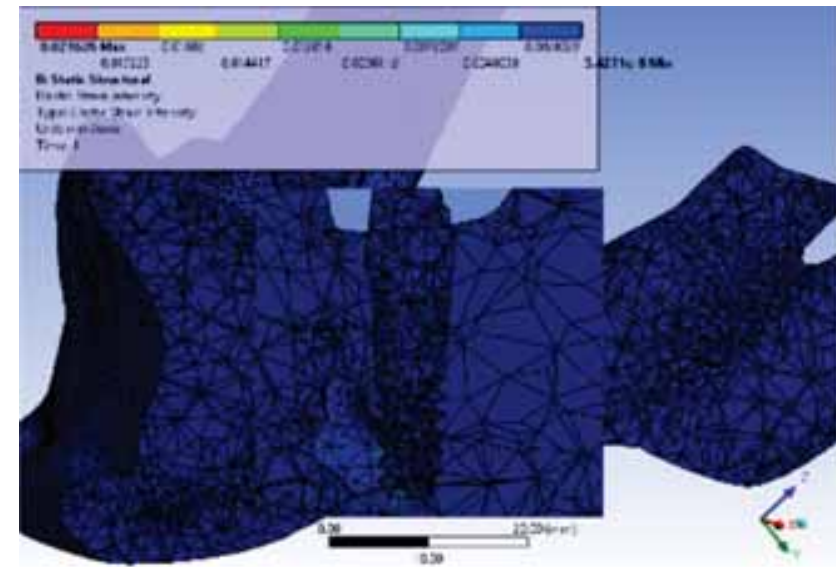

FIGURA 5. Intensitatea deformației relative elastice a modelului 1

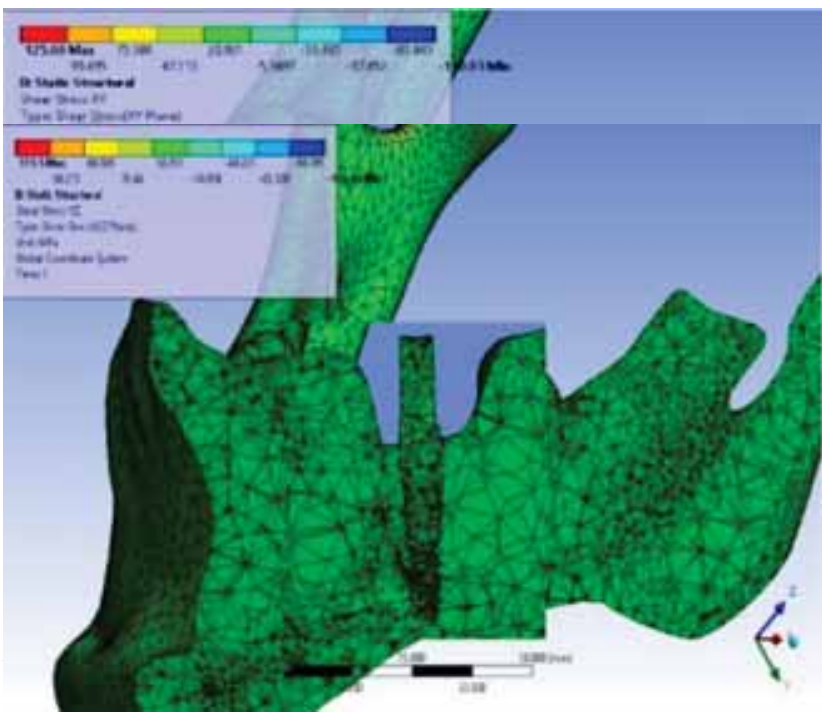

FIGURA 7. Tensiunea de forfecare a modelului 1 în planul $Y Z$

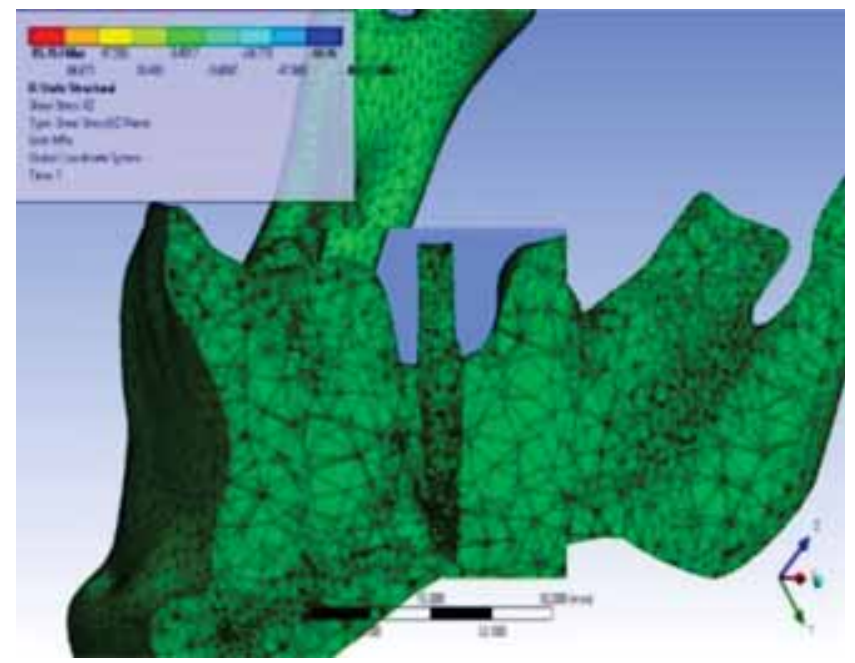

FIGURA 8. Tensiunea de forfecare a modelului 1 în planul $X Z$
Deformația elastică relativă echivalentă a variat între 4,0842e-008 mm/mm şi 1,7878e-002 mm/ $\mathrm{mm}$. Se pot observa deformații relative $\mathrm{cu}$ valori reduse la nivelul apexului implantului şi la nivelul primelor spire ale acestuia.

Deformația relativă elastică principală maximă a variat între $-2,0628 \mathrm{e}-005 \mathrm{~mm} / \mathrm{mm}$ şi $1,827 \mathrm{e}-002$ $\mathrm{mm} / \mathrm{mm}$. Deformația relativă elastică tangențială maximă a variat între un minim de 5,4271e-008 $\mathrm{mm} / \mathrm{mm}$ şi un maxim de $2,1626 \mathrm{e}-002 \mathrm{~mm} / \mathrm{mm}$. Se pot observa deformații relative cu valori reduse la nivelul apexului implantului şi primelor spire.

Intensitatea deformației relative elastice a variat între 5,4271e-008 mm/mm şi 2,1626e-002 mm/ $\mathrm{mm}$. De asemenea, se pot observa deformații relative cu valori reduse la nivelul vârfului implantului şi primelor spire.

În ceea ce priveşte tensiunile de forfecare la nivelul modelului 1 , acestea au variat:

- în planul XY între -110,03 MPa şi 125,69 MPa;

- în planul YZ între -116,08 MPa şi 111,5 MPa;

- în planul XZ între -86,05 MPa şi 85,763 MPa.

La aplicarea forței experimentale de $200 \mathrm{~N}$, am constatat că la nivelul porțiunii inferioare a implantului au apărut presiuni de comprimare asupra osului mandibular. La nivelul apexului implantului, am constatat că apare o tendință foarte uşoară de alunecare în raport cu substratul osos, distanța de alunecare variind între 0 şi 8,9001e-004 mm. Tot la acest nivel apare o tendință uşoară de penetrare în osul mandibulei, de până la 2,5994e-003 mm. Corespunzător celor semnalate anterior, la nivelul vârfului implantului, pe primele spire, apare o tasare uşoară a osului mandibulei (pierderea contactului), ce variază între $-0,11092$ şi 0 mm.

Modelul 2 a fost alcătuit din implantul osteointegrat din zirconie inserat în osul mandibular şi a cuprins 161.033 noduri şi 95.361 elemente finite.

Proprietăţile izotrope de elasticitate ale zirconiei luate în calcul în cadrul analizei prin metoda elementelor finite sunt prezentate în Tabelul 4.

TABELUL 4. Proprietăți izotrope de elasticitate ale zirconiei din care este confecționat implantul

\begin{tabular}{|c|c|c|c|}
\hline $\begin{array}{c}\text { Modul Young } \\
\text { (MPa) }\end{array}$ & $\begin{array}{c}\text { Coeficientul } \\
\text { Poisson }\end{array}$ & $\begin{array}{c}\text { Modul Bulk } \\
\text { (MPa) }\end{array}$ & $\begin{array}{c}\text { Modul de } \\
\text { forfecare (MPa) }\end{array}$ \\
\hline $2,05 \mathrm{e}+005$ & 0,31 & $1,7982 \mathrm{e}+005$ & 78.244 \\
\hline
\end{tabular}

Deformația absolută totală a modelului 2 a variat între un minim de $1,995 \mathrm{~mm}$ şi un maxim de 
4,5876 $\mathrm{mm}$, iar valorile deformației totale la nivelul elementelor implantului sunt, de asemenea, ca şi în cazul implantului din aliaj de titan analizat anterior, medii spre mari comparativ cu cele de la nivelul mandibulei.

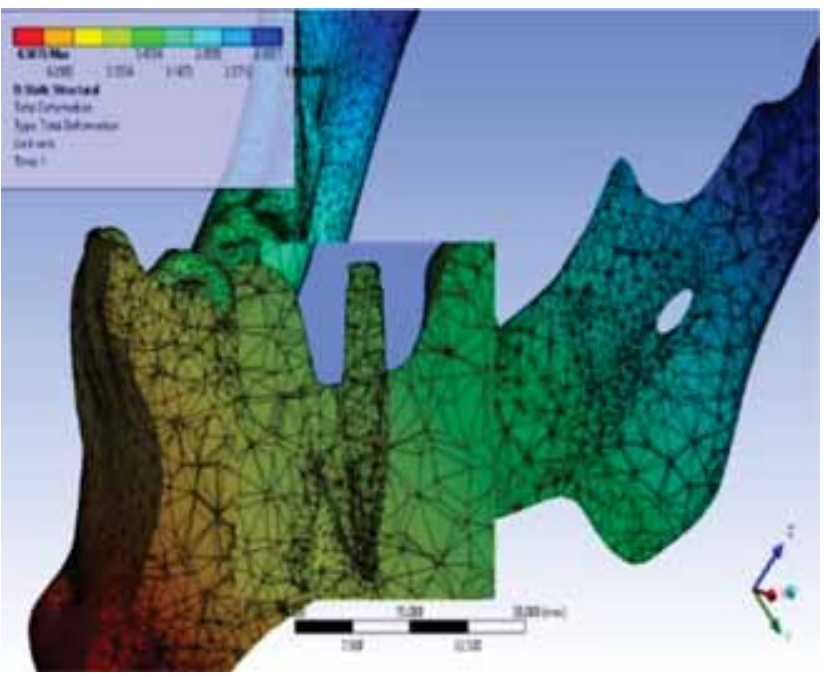

FIGURA 9. Deformația absolută totală a modelului 2

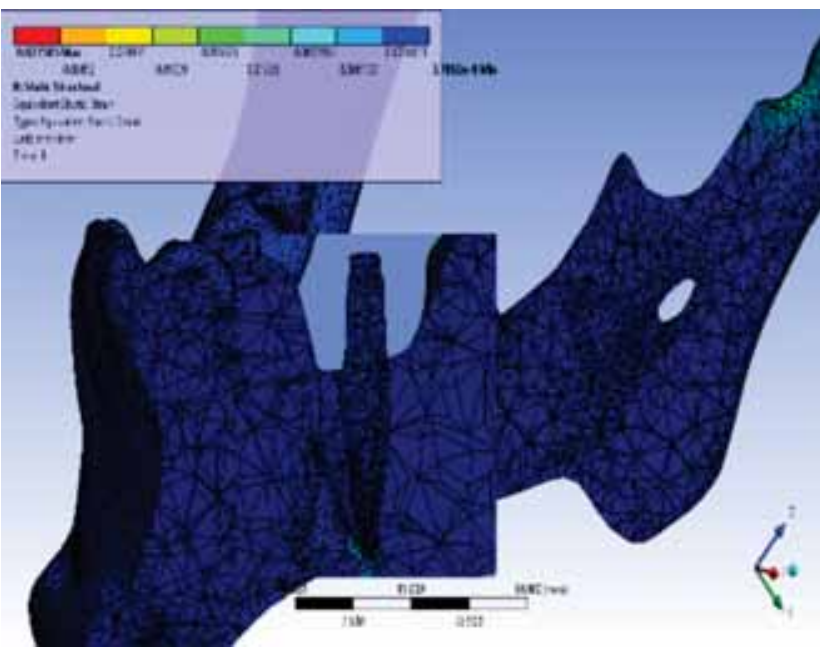

FIGURA 10. Deformatia relativă elastică echivalentă a modelului 2

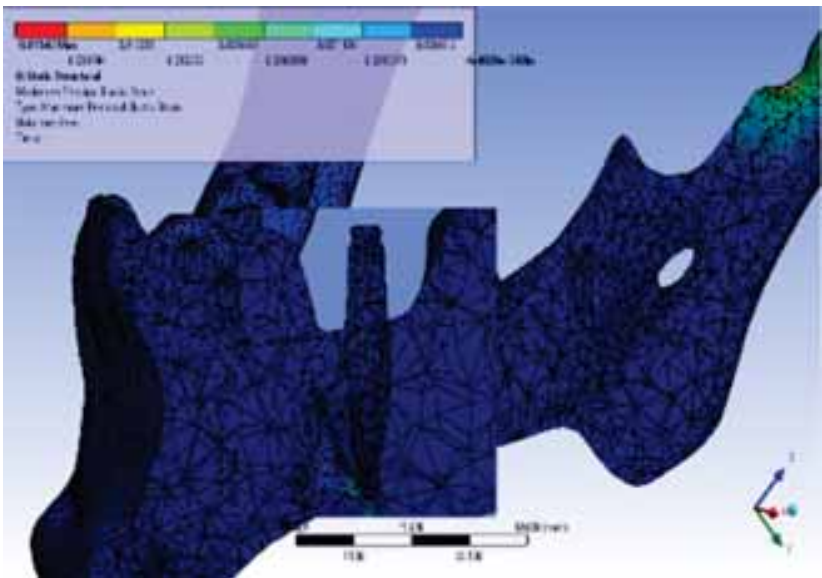

FIGURA 11. Deformația relativă elastică principală maximă a modelului 2

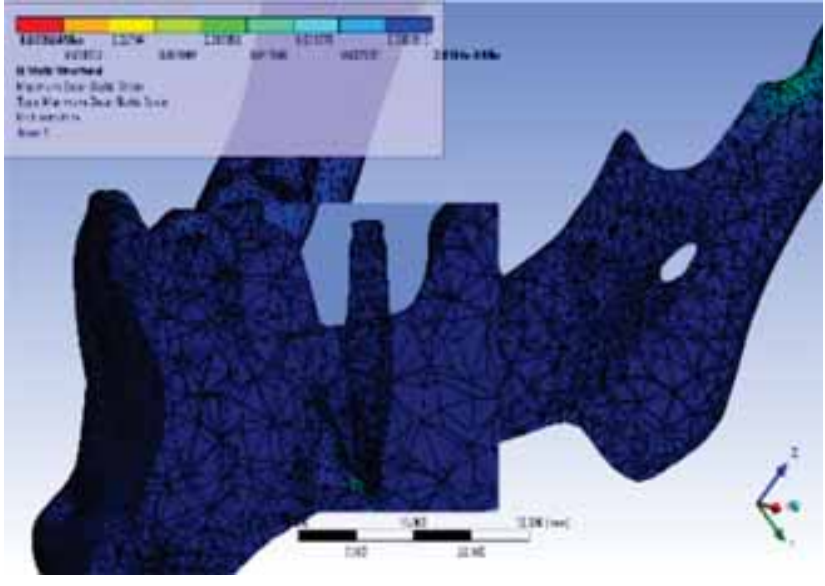

FIGURA 12. Deformația relativă elastică tangențială maximă a modelului 2

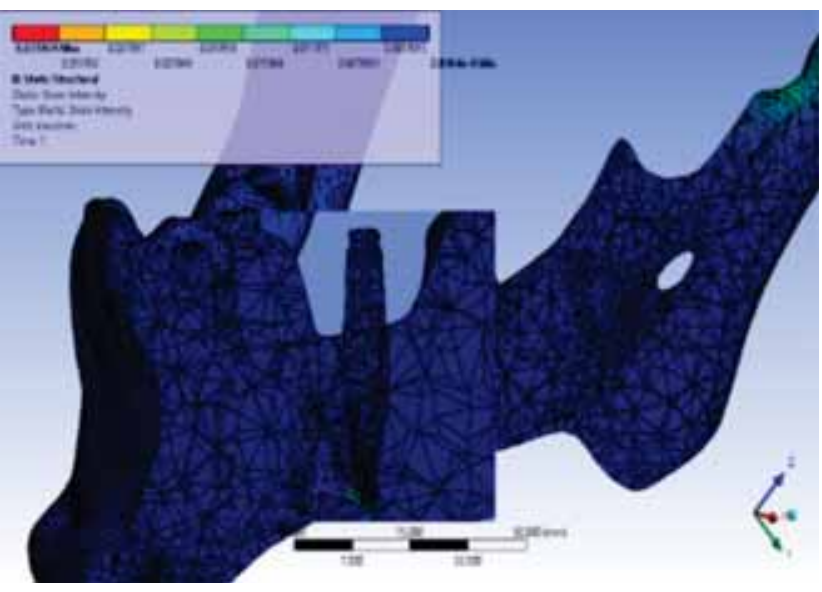

FIGURA 13. Intensitatea deformației relative elastice a modelului 2

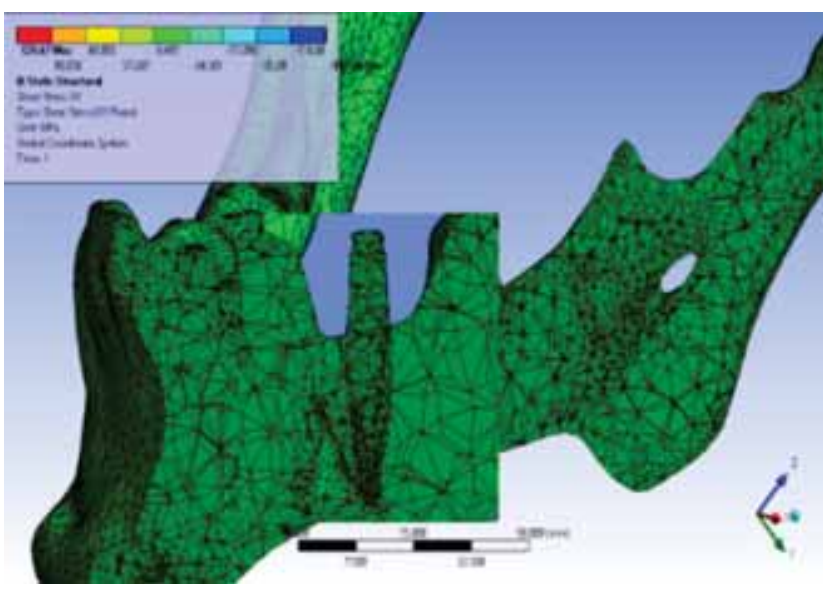

FIGURA 14. Tensiunea de forfecare a modelului 2 în planul $X Y$

Deformația elastică relativă echivalentă a modelului 2 a variat între $3,7925 \mathrm{e}-008 \mathrm{~mm} / \mathrm{mm}$ şi 2,7603e-002 $\mathrm{mm} / \mathrm{mm}$.

Deformația relativă elastică principală maximă a variat între $-6,4929 \mathrm{e}-005 \mathrm{~mm} / \mathrm{mm}$ și $1,548 \mathrm{e}-002$ $\mathrm{mm} / \mathrm{mm}$. Deformația relativă elastică tangențială 
maximă a variat între un minim de 2,8117e-008 $\mathrm{mm} / \mathrm{mm}$ şi un maxim de $3.5944 \mathrm{e}-002 \mathrm{~mm} / \mathrm{mm}$. Ca şi în cazul implantului din aliaj de titan, se pot observa deformatiii relative cu valori reduse la nivelul apexului implantului şi la nivelul primelor spire ale acestuia.

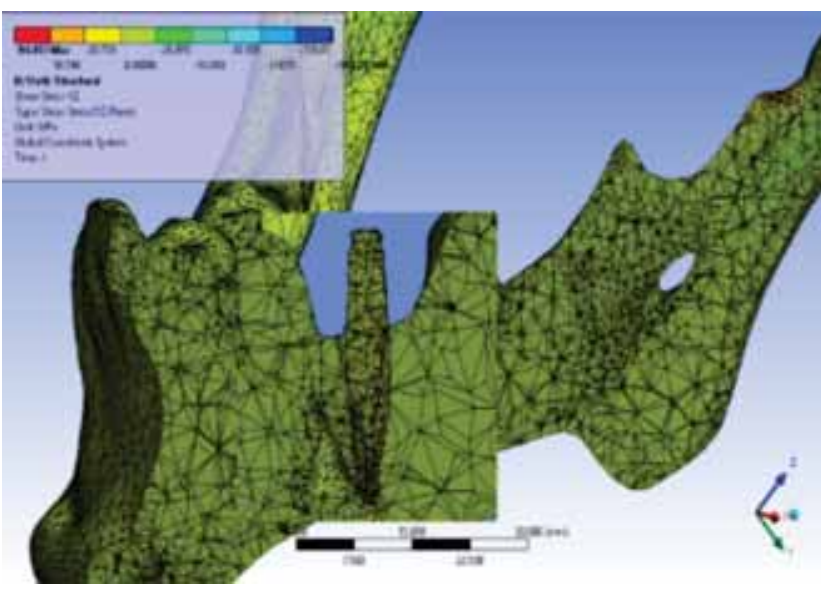

FIGURA 15. Tensiunea de forfecare a modelului 2 în planul YZ

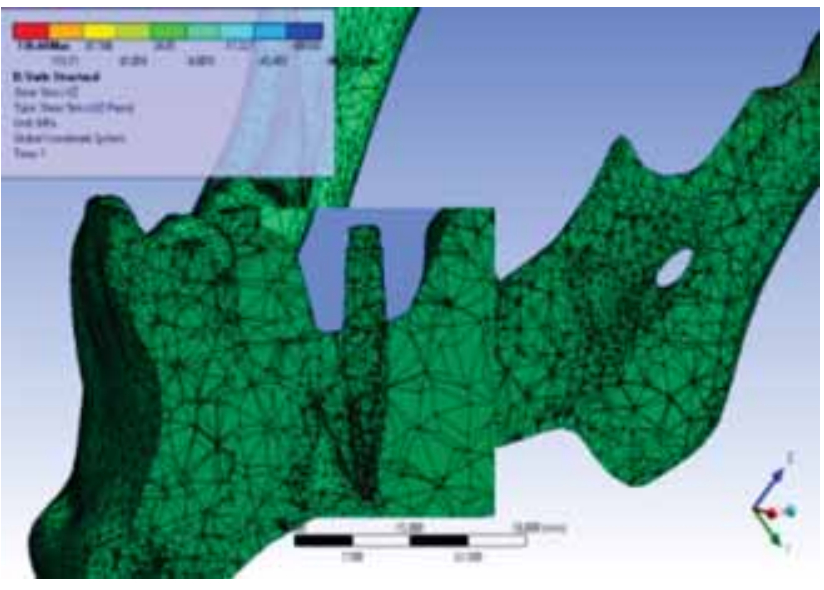

FIGURA 16. Tensiunea de forfecare a modelului 2 în planul $X Z$

Intensitatea deformaţiei relative elastice a variat între $2,8117 \mathrm{e}-008 \mathrm{~mm} / \mathrm{mm}$ și $3,5944 \mathrm{e}-002 \mathrm{~mm} /$ mm, având valori reduse la nivelul vârfului implantului.

În ceea ce priveşte tensiunile de forfecare la nivelul modelului 2 , acestea au variat:

- în planul XY între -149,58 MPa şi 130,67 MPa;

- în planul YZ între -168,57 MPa şi 85,309 MPa;

- în planul XZ între -96,625 MPa şi 140,9 MPa.

La nivelul apexului implantului din zirconie, am constatat, similar implantului din aliaj de titan, că apare o tendință foarte uşoară de alunecare în raport cu substratul osos. În acest caz, distanța de alunecare a variat între 0 şi $1,2863 \mathrm{e}-003 \mathrm{~mm}$. Tot la acest nivel, apare o tendință uşoară de penetrare în osul mandibulei, de până la 7,2866e-004 mm. Corespunzător celor semnalate anterior, la nivelul vârfului implantului pe prima spiră apare o tasare uşoară a osului mandibulei, ce variază între $-0,13491$ şi 0 $\mathrm{mm}$.

Tensiunea de frecare crescută, dar cu valori minimale în general, apare pe prima spiră a implantului, cu o valoare maximă de $1.344,6 \mathrm{MPa}$. Valorile forței de reacțiune dezvoltate au fost aceleaşi ca şi în cazul implantului din aliaj de titan.

\section{DISCUŢII}

Distribuția forțelor masticatorii în jurul dinților, implicațiile acestora asupra țesuturilor parodontale şi materialelor dentare din care sunt confecționate restaurările protetice reprezintă subiecte destul de dezbătute în literatura recentă $(6,24-27)$. În cazul supraîncărcării ocluzale (28), pot apărea fie pierderea osoasă, fie pierderea totală a osteointegrării implanturilor (29). Cu toate acestea, în ambele situații, țesutul osos periimplantar prezintă o rată ridicată de remodelare (30). În cazul transferului eficient de forță între implant şi suportul osos, încărcarea ocluzală poate stimula neo-osteogeneza şi poate favoriza osteointegrarea (31).

Unii autori (32) au sugerat că, în cazul creşterii diametrului implantului inserat, problemele de biomecanică sunt rezolvate prin mărirea interfeței osimplant.

Analiza cu elemente finite reprezintă o abordare eficientă privind studiul comportării mecanice a sistemelor cu geometrie complexă şi a materialelor cu proprietăți mecanice diferite supuse diferitelor moduri de încărcare (33).

Comportarea la simulări mecanice a celor două tipuri de implanturi din studiul nostru a fost diferită, atât datorită proprietăților de material diferite, cât şi a formei geometrice diferite.

Zirconia are un coeficient Poisson mai apropiat de al osului cortical $(0,31$ față de 0,3$)$ comparativ cu situația aliajului de titan $(0,342$ față de 0,3$)$.

Acest lucru are o importanță deosebită în condițiile solicitării de masticație, deoarece implantul de zirconie atenuează până la anulare efectul de blocare a transferului de tensiuni între implant şi os (efectul „stress shielding") şi, ca urmare, tranziția efortului către mandibulă este lină, fără a conduce la concentrarea eforturilor la interfața implant-os. 


\section{CONCLUZIE}

Pe baza analizei cu elemente finite efectuate, comportamentul biomecanic al implantului din zirconie este mai bun decât comportamentul biomeca-

\section{BIBLIOGRAFIE}

1. Maminskas J., Puisys A., Kuoppala R., Raustia A., Juodzbalys $\mathbf{G}$. The prosthetic influence and biomechanics on peri-implant strain: A systematic literature review of finite element studies. J Oral Maxillofac Res. 2016; 7:e4.

2. Chang Y., Tambe A.A., Maeda Y., Wada M., Gonda T. Finite element analysis of dental implants with validation: To what extent can we expect the model to predict biological phenomena? A literature review and proposal for classification of a validation process. International Journal of Implant Dentistry (2018) 4:7 DOI 10.1186/s40729-018-0119-5.

3. Gass S.I. Decision-adding models: Validation, assessment and related issues for policy analysis. Oper Res. 1983; 31:603-31.

4. Sotto-Maior B.S., Mercuri E.G., Senna P.M., Assis N.M., Francischone C.E., Del Bel Cury A.A. Evaluation of bone remodeling around single dental implants of different lengths: A mechanobiological numerical simulation and validation using clinical data. Comput Methods Biomech Biomed Engin. 2016; 19:699-706.

5. Wang C., Li Q., McClean C., Fan Y. Numerical simulation of dental bone remodeling induced by implant-supported fixed partial denture with or without cantilever extension. Int $J$ Numer Method Biomed Eng. 2013; 29:1134-47.

6. Cicciù M., Cervino G., Bramanti E., Lauritano F., Lo Gudice G., Scappaticci L. et al. FEM analysis of mandibular prosthetic overdenture supported by dental implants: Evaluation of different retention methods. Comput Math Methods Med. 2015:16. http://dx.doi. org/10.1155/2015/943839.

7. Topkaya T., Solmaz M.Y. The effect of implant number and position on the stress behavior of mandibular implant retained overdentures: A threedimensional finite element analysis. J Biomech. 2015;48:2102-9.

8. Costa C., Peixinho N., Silva J.P., Carvalho S. Study and characterization of the crest module design: A 3D finite element analysis. J Prosthet Dent. 2015; 113:541-7.

9. Arat Bilhan S., Baykasoglu C., Bilhan H., Kutay O., Mugan A. Effect of attachment types and number of implants supporting mandibular overdentures on stress distribution: $A$ computed tomography-based 3D finite element analysis. J Biomech. 2015; 48:130-7.

10. Abou-Emara M., Spintig T., Lackmann J., Müller W.D. Finite element analysis of the biomechanical effects of PEEK dental implants on the peri-implant bone. J Biomech. 2015; 48:1-7.

11. Capek L., Simunek A., Henys P., Dzan L. The role of implant's surface treatment to its preload. Comput Methods Biomech Biomed Engin. 2014; 17(Suppl 1):8-9.

12. Brunski J.B. Biomechanical aspects of the optimal number of implants to carry a cross-arch full restoration. Eur J Oral Implantol. 2014; 7(Suppl 2):S111-31.

13. Harirforoush R., Arzanpour S., Chehroudi B. The effects of implant angulation on the resonance frequency of a dental implant. Med Eng Phys. 2014; 36:1024-32. nic al implantului din titan, deoarece implantul din zirconie, prin caracteristicile sale, atenuează transferul tensiunilor dintre el şi os, menajând osteointegrarea.

Conflict of interest: none declared Financial support: none declared

14. Xiao W., Li Z., Shen S., Chen S., Wang Y., Wang J. Theoretical role of adjunctive implant positional support in stress distribution of distal-extension mandibular removable partial dentures. Int J Prosthodont. 2014; 27:579-81.

15. Kim S., Kim S., Choi H., Woo D., Park Y.B., Shim J.S. et al. A three-dimensional finite element analysis of short dental implants in the posterior maxilla. Int J Oral Maxillofac Implants. 2014; 29:e155-64.

16. van Staden R.C., Li X., Guan H., Johnson N.W., Reher P., Loo Y.C. A finite element study of short dental implants in the posterior maxilla. Int J Oral Maxillofac Implants. 2014; 29:e147-54.

17. Piotrowski B., Baptista A.A., Patoor E., Bravetti P., Eberhardt A., Laheurte P. Interaction of bone-dental implant with new ultra low modulus alloy using a numerical approach. Mater Sci Eng C Mater Biol Appl. 2014; 38:151-60.

18. dos Santos M.B., Bacchi A., Correr-Sobrinho L., Consani R.L. The influence of clip material and cross sections of the bar framework associated with vertical misfit on stress distribution in implant-retained overdentures. Int $\mathrm{J}$ Prosthodont. 2014; 27:26-32.

19. Santiago Junior J.F., Pellizzer E.P., Verri F.R., de Carvalho P.S. Stress analysis în bone tissue around single implants with different diameters and veneering materials: A 3-D finite element study. Mater Sci Eng C Mater Biol Appl. 2013; 33:4700-14.

20. Ding X., Liao S.H., Zhu X.H., Wang H.M. Influence of orthotropy on biomechanics of peri-implant bone in complete mandible model with full dentition. Biomed Res Int. 2014; 2014:709398.

21. Gačnik F., Ren Z., Hren N.I. Modified bone densitydependent orthotropic material model of human mandibular bone. Med Eng Phys. 2014; 36:1684-92.

22. Kang N., Wu Y.Y., Gong P., Yue L., Ou G.M. A study of force distribution of loading stresses on implant-bone interface on short implant length using 3-dimensional finite element analysis. Oral Surg Oral Med Oral Pathol Oral Radiol. 2014; 118:519-23.

23. Comăneanu R.M., Barbu H.M., Vlăsceanu D., Târcolea M. Numerical analyses of stresses and strains in bone - implant assembly. Key Engineering Materials, vol 583 (2014), pag. 169-174, online available since 2013/Sep/10 at www. scientific.net/KEM.583.169, ISSN 1662-9795.

24. Alhasanyah A., Vaidyanathan T.K., Flinton R.J. Effect of core thickness differences on post-fatigue indentation fracture resistance of veneered zirconia crowns. Journal of Prosthodontics, vol. 22, no. 5, pp. 383-390, 2013.

25. Cicciu M., Bramanti E., Matacena G., Guglielmino E., Risitano G. FEM evaluation of cemented-retained versus screwretained dental implant single-tooth crown prosthesis. International Journal of Clinical and Experimental Medicine, vol. 7, no. 4, pp. 817-825, 2014.

26. Chun K.J., Lee J.Y. Comparative study of mechanical properties of dental restorativematerials and dental hard 
tissues in compressive loads. Journal of Dental Biomechanics, vol. 5, 2014.

27. Liao Z., Yoda N., Chen J. et al. Simulation of multi-stage nonlinear bone remodeling induced by fixed partial dentures of different configurations: A comparative clinical and numerical study. Biomechanics and Modeling in Mechanobiology, vol. 16, no. 2, pp. 411-423, 2017.

28. Trivedi S. Finite element analysis: A boon to dentistry. J Oral Biol Craniofac Res. 2014 Sep-Dec; 4(3):200-3. http://dx.doi. org/10.1016/j.jobcr.2014.11.008. PMid:25737944.

29. Mannarino F.S., Francischone C.A., de Carvalho R.S., Sotto-Maior B.S., Francischone C.E, Analysis of the distribution of stress and deformation in single implantsupported prosthetic units in implants of different diameters. Rev Odontol UNESP. 2016 Sept-Oct; 45(5): 247-252.

30. Chang M., Chronopoulos V., Mattheos N. Impact of excessive occlusal load on successfully-osseointegrated dental implants: A literature review. J Investig Clin Dent. 2013 Aug; 4(3):142-50. http://dx.doi.org/10.1111/jicd.12036. PMid:23918506.

31. Duyck J., Vandamme K. The effect of loading on periimplant bone: a critical review of the literature. J Oral Rehabil. 2014 Oct; 41(10):783-94. http://dx.doi.org/10.1111/joor.12195. PMid:24889500.

32. Klein M.O., Schiegnitz E., Al-Nawas B. Systematic review on success of narrow-diameter dental implants. Int J Oral Maxillofac Implants. 2014; 29(Suppl):43-54. http://dx.doi. org/10.11607/jomi.2014suppl.g1.3. PMid:24660189.

33. Kant R., Shrikrishna Joshi N., Uday Dixit S. An integrated FEM-ANN model for laser bending process with inverse estimation of absorptivity. Mechanics of Advanced Materials and Modern Processes, Vol. 1, 2015, pp. 08-15. 